\title{
Sağlık Kuruluşlarında Değer Zinciri Yönetiminin Değerlendirilmesi
}

\author{
Yiğit Kerem YILDIZ*
}

\section{$\ddot{O} \mathbf{z}$}

Sağlık kuruluşları varlıklarını sürdürebilmek için sağlık hizmetlerini sunmaları gerekir. Hizmetleri sunmak için sağllk kuruluşlarının hastaların beklentilerine cevap vermesi ve onların elinde bulundurduğu maddi ile manevi kaynakları kullanmasını sağlamaları gerekir. Buna değer denir. $\mathrm{Bu}$ değerin hizmet sunumuna yansıtılmasına yardımcı olan değer zinciri yönetimi kavramı ortaya çıkmıştır. Değer zinciri yönetimi, bir mal veya hizmetin üretiminden sunumuna kadar olan bütün aşamalarda değer katan örgütsel faaliyetlerinin yönetimidir. Buradan anlaşlacağı üzere sağlık hizmetlerinin değer katılarak üretilmesinde rol oynayan bütün paydaşların faaliyetlerini de içermektedir. Sağlık sektöründe değer zinciri yönetimini genel anlamda değerlendirmek zordur. Sektör içerisinde yer alan paydaşlar ayrı ayrı değerlendirilmelidir. Bu çalışmanın amacı, sağlık hizmetlerinin sunumunda önemli rol oynayan sağllk kuruluşlarında değer zinciri yönetiminin değerlendirilmesidir. Bu amaca ulaşılması için sağllkta değer zinciri yönetimiyle ilgili çalışmalar derlenmiştir. Yapılan değerlendirmelere göre kamu sağlık kuruluşlarının değer zinciri yönetimini özel sağlık kuruluşlarına göre daha geniş kapsamda tanımlamaktadır. Özel sağlık kuruluşları kamu sağlık kuruluşları kadar geniş bir şekilde değer zinciri yönetimini tanımlamamasına rağmen yeniliğe açık olması ve niş pazarları araştırması gibi faaliyetler yapması yönünden değer zinciri yönetimine katkıda bulunmaktadır. Ancak, kamu ve özel sağlık kurumları değer zinciri yönetiminin farkında olmalı ve değer zinciri yönetimi için faaliyetlerde bulunmalıdır.

Anahtar Sözcükler: Değer zinciri, değer zinciri yönetimi, sağllk kuruluşları.

\section{Derleme Makale (Review Article)}

Geliş / Received: 16.04.2019 \& Kabul / Accepted: 10.05.2019

* Doktora Öğrencisi, İstanbul Medipol Üniversitesi, Sağlık Bilimleri Enstitüsü, Sağlık Yönetimi

Doktora Programı, İstanbul, Türkiye, E-posta: yigitkeremyildiz93@gmail.com

ORCID ID https://orcid.org/0000-0002-2976-9169 


\title{
Evaluation of Value Chain Management in Healthcare Institutions
}

\begin{abstract}
Health care organizations are required to provide health services to maintain their existence. In order to provide services, health care organizations must respond to the expectations of patients and ensure that they use the material and spiritual resources they hold. It is called value. The concept of value chain management, which helps to reflect this value to service delivery has emerged. Value chain management is the management of organizational activities that add value in all stages from the production to the presentation of a good or service. As can be understood from this point of view, it includes the activities of all stakeholders who play a role in the production of value-added of health services. It is difficult to assess the value chain management in the health sector in general terms. Stakeholders within the sector should be evaluated separately. The aim of this study is to evaluate the value chain management in health institutions that play an important role in the provision of health services. In order to achieve this goal, studies on value chain management in health have been reviewed. Based on assessments, public health institutions define value chain management more broadly than private health institutions. Although private health institutions do not define value chain management as broadly as public health institutions, they contribute to value chain management in terms of being open to innovation and conducting activities such as niche market research. However, public and private health institutions have to be aware of the value chain management and perform activities for value chain management.
\end{abstract}

Keywords: Value chain, value chain management, healthcare facilities.

\section{Giriş}

Sağlık kuruluşları varlıklarını sürdürebilmek için sağlık hizmetlerini sunmaları gerekir. Hizmetleri sunmak için hastaların beklentilerine cevap vermesi ve elinde bulundurduğu maddi ve manevi kaynakları kullanmasını kabul ettirmesi gerekir. $\mathrm{Bu}$ duruma çözüm niteliği taşıyan değer zinciri yönetimi kavramı ortaya çıkmıştır. Sağlık kuruluşlarının mevcut sunum süreçlerini etkileyen değer zinciri yönetimi ilk olarak Michael Porter tarafından ortaya çıkmıştır ${ }^{1}$. Değer zinciri yönetimi, bir mal veya hizmetin daha düşük bir fiyatla satılmasına dayanan anlayışın şirketleri batırmasının ardından ortaya çıkmıştır. Bu yönetim anlayışının temelinde müşteriye değer vermenin rekabet ortamında kuruluşların daha başarılı olacakları yatmaktadır. 
Sağlık kuruluşları hasta odaklı bir anlayışla hizmetleri sunmaktadır. Hasta odaklı anlayışı değer zinciri yönetiminin sağlık alanına da yayılmasına yol açmıştır. Bununla birlikle hastaların finansal yüklerini azaltma istekleri, özellikle özel hastanelerin birleşerek büyümesi gibi çeşitli yollarla ölçek ekonomilerini ve pazar paylarını büyütme istekleri ve e-ticaret gibi teknolojinin işletme faaliyetlerinde aktif rollerde görev alması değer zinciri yönetiminin sağlık kuruluşları açısından önemini ortaya koymaktadır.

$\mathrm{Bu}$ çalışmanın amacı, sağlık hizmetlerinin sunumunda önemli rol oynayan sağlık kuruluşlarında değer zinciri yönetiminin değerlendirilmesidir. $\mathrm{Bu}$ çalışmanın yapılabilmesi için sağlıkta değer zinciri yönetimine yönelik çalışmalar derlenmiştir.

\section{Değer Zinciri Yönetimi Kavramı}

Değer zinciri yönetimi kavramını açıklamadan önce değer kavramının ne olduğu bilinmelidir. Değer, bir mal veya hizmete yönelik, tüketicilerin bu mal ya da hizmeti elde etmek için para gibi bazı kaynaklar kullanmayı kabul edecekleri niteliklere veya herhangi bir başka özelliklerinin her birine verilen addır². Tüketici için önemli olan değerin sunumu değerin kendisi kadar önemli olan bir noktadır. Değer zinciri, mal veya hizmetin en baştan son aşamaya kadar olan bütün aşamalarda değer katan örgütsel faaliyetlerinin tümüdür. Değer zinciri, çok geniş katılımcılara kadar uzanabilmektedir3. $\mathrm{Bu}$ faaliyetler ile bilgilerin yönetilmesi amacıyla değer zinciri yönetimi kavramı ortaya çıkmıştır. Değer zinciri yönetimi verimlilikten ziyade daha çok etkililiğe odaklanmaktadır ve en yüksek değeri yaratmayı amaçlamaktadır.

Bir örgütün değer zinciri yönetimi konusunda başarılı olması için öncelikle değer zinciri yönetimindeki bileşenleri bilmesi gerekir. Değer zinciri yönetimi bileşenleri şu şekilde sıralanabilir²:

- Eşgüdüm ve İşbirliği

- Teknolojik Yatırım

- Örgütsel Süreçler

- Liderlik

- Çalışanlar ve İnsan Kaynakları

- Örgütsel Kültür ve Tutum

- Değer Zinciri Yönetimini Etkileyen Faktörler 
Değer zinciri yönetimini oluşturan bileşenlerin yanında bu yönetim faaliyetini etkileyen faktörler de bulunmaktadır. Kuruluşlar bu faktörlerin etkilerini kontrol altına almalıdır. Değer zinciri yönetimi konusunda üstesinden gelmeleri gereken zorluklar şu şekilde sınıflandırılabilir²:

- Örgütsel Sinirlar

- Kültürel Tutumlar

- Yetkinlikler

- Çalışanlar

\section{Sağlık Kuruluşlarında Değer Zinciri Yönetimi}

Sağlık kuruluşlarında değer zinciri yönetiminde benimsenen görüş Michael Porter tarafından belirtilen değer zinciri kavramıdır. Porter değer zinciri yönetimini, bir ürün veya hizmet üretmek için gerekli olan hammaddenin girişinden kullanıcılara sunulacak olan ürünün üretimine kadar olan süreç olarak tanımlamaktadır ve değer zinciri yönetiminde mutlaka dikkate alınması gereken kavramlar şunlardır:

- Kuruluş Yapısı

- İnsan Kaynakları Yönetimi

- Teknolojik Gelişim

- Temin Etme

- Lojistik Yönetimi

Sağlık hizmetleri kamu ve özel kuruluşlar tarafından sunulmaktadır. Bu kuruluşlar arasında bazı farklılıklar bulunmaktadır. Bu farklılıkları belirtmeden sağlık kuruluşlarında değer zinciri yönetimini değerlendirmek sağlıklı olmayacaktır. Bilindiği üzere kamu kuruluşları sağlık hizmetlerinin bireylere ulaştırmak için para harcamakta iken özel kuruluşlar ise sağlık hizmetlerinden belirli bir kazanç elde etmek için hizmet sunmaktadır. Hem kamu hem de özel sağlık kuruluşları verimlilik gibi kuruluşun ayakta kalması için gerekli olan prensipleri benimsemektedir. Kamu ve özel kuruluşlarının özellikle operasyonel hedeflerinin farklı olmasından dolayı teşvik sistemlerinde farklı stratejiler uygulamaktadır5. Kamu kuruluşları sağlığın 
geliştirilmesi, sağlı̆̆ı korunmasına ve sağlık hizmetlerine olan talebin mümkün oldukça azalmasına yönelik faaliyetlerini yürütürken özel sağlık kuruluşları hizmet verme hacimlerini genişleterek paket hizmetler aracılığıla hizmete yönelik talebin artmasını istemektedir. Kamu ve özel sağlık kuruluşları kalitenin geliştirilmesine ve hasta memnuniyetine önem vermektedir. Ancak özel sağlık kuruluşları kaliteye ve memnuniyete önem vermesinin temel sebebi, hissedar değerlerinin korunması ve olumlu geri dönüşler sayesinde hastaların aynı kuruluşu tekrar tercih etmelerinin sağlanmasıdır. Kamu ve özel sağlık kuruluşları sağlık sistemlerinde yaşanan sorunlara yönelik tek başlarına çözebilme yetenekleri bulunmamaktadır ${ }^{6}$.

Sağlıkta değer zinciri yönetimine yönelik yapılan bir çalışmada kamu sağlık kuruluşları ile özel sağlık kuruluşlarının değer zinciri yönetimi bakımından değerlendirmiştir ve bazı farklılıkların olduğunu belirterek şu şekilde açıklamıştır7:

a) Kamu Sağlık Kuruluşlarında Değer Zinciri Yönetimi: Kamu sağlık kuruluşlarında değer zinciri yönetimi konusunda özellikle kalitenin artması ve hasta şikâyetlerinin azalması bütün ülkelerde bulunan kamu sağlık kuruluşlarının arzuları olmasından dolayı hasta deneyimleri ön plana çıkmaktadır. Sağlık kapsamının geniş olmasından dolayı mülteciler de dâhil olmak üzere herkes sağlık hizmetlerini kullanabilme imkânının verilmesi değer zinciri yönetimi açısından önemlidir. Ayrıca kamu sağlık kuruluşlarının birçoğunun hastaların bütün sağlık hizmetlerini aynı yerden karşılamasına yönelik tasarlanmış olması değer zinciri yönetimi için diğer bir avantajdır. Kamu sağlık kuruluşları gerekli duyduğu insan kaynağı ihtiyacına yönelik araştırma sürecine özel sağlık kuruluşları kadar uzun bir şekilde girmemektedir. Aynı zamanda daha fazla personele sahip olma konusunda tereddüt duymamaktadır. Kamu sağlık kuruluşları birinci basamak sağlık hizmetlerinden rehabilite edici hizmetlere kadar çeşitli hizmetler konusunda diğer kamu kuruluşlarıyla bağlantılı bir şekilde hareket etmektedir. Böylece sağlı̆̆ın geliştirilmesi ve sağlık eğitimi konularına odaklanılmasına yardımcı olmaktadır. Değer zinciri yönetimi konusunda kamu kuruluşlarının zayıf yanları da bulunmaktadır. Bu zayıf yanların başında hizmetlere erişimin giderek kolaylaşmasıyla beraber kuruluşların herkese mümkün olan en iyi sağlık hizmetlerinin sunulurken sağlık kuruluşlarının maliyet-etkililiğe yönelik olumsuz etki yaratabilme olasılığı bulunmaktadır. Bunun oluşmasındaki sebep eğer bir kamu kuruluşunda maliyet ve kaliteye yönelik bilinç oluşturulmadığı takdirde meydana 
gelmektedir. Değer zinciri yönetimindeki diğer bir zayıf nokta, zincir içerisinde yer alan tedarikçi kuruluşlar ile hastaların sağlık hizmetleri konusundaki maliyetlere yönelik bilinçli olmadığı durumlarda sağlık hizmetleri kullanılırken suiistimale uğrama tehlikeleriyle karşılaşabilmektedir. Hastalar değer zinciri yönetiminin önemli bir parçasıdır ve hizmet ihtiyaçlarını çoğu zaman kamu kuruluşlarından karşılamaktadır. Fakat hastaların yapılacak testler ve bu testlerin fiyatları ile maliyetleri konusunda bilgi düzeyinin düşük olması ahlaki tehlikeye yol açma ihtimali bulunmaktadır. Kamu sağlık kuruluşları değer zinciri yönetimi konusunda ilerleyen dönemlerde web site, sosyal medya veya uygulamalar aracılığıyla teknolojik olarak hastalarla iletişime geçmesine yönelik adımlar atılması beklenilmektedir. Aynı zamanda özellikle koruyucu hizmetleri veren uzman sağlık personelinin sevk zinciri konusunda hastalara ikinci ve üçüncü basamak sağlık kuruluşlarına gidebilmeleri için gerekli olan durumlar konusunda bilgilendirici olması değer zinciri yönetimi açısından da önemlidir. Fakat buradaki önemli fırsatların yanında kamu kuruluşlarında değer zinciri yönetimi açısından bazı tehditler vardır. Bu tehditlerin başında gelen kavram kültür faktörüdür. Eğer bir ülkede sağlık hizmetlerinin gereksiz bir şekilde kullanılması, acil servise yapılan gereksiz başvuru kültürü var ise bu durum değer zinciri yönetimi için bir tehdittir. Ayrıca ayaktan tedavi hizmetlerini almış veya diğer hastalara göre daha az cerrahi müdahale geçirmiş olan hastaların hizmet aldıkları kuruluştan aynı gün içerisinde taburcu olmamaları zaman ve kaynak kaybına yol açarak hizmete gerçekten ihtiyaç duyan hastaların bekletilmesine yol açmaktadır. Bu durum değer zinciri yönetimi içerisinde yer alan paydaşlar açısından bir tehdittir. Bütün ülkelerde yaşlı nüfus giderek artmakta ve onların sağlık hizmetlerine ulaşması büyük bir önem arz etmektedir. Yaşlıların özellikle sağlık hizmetlerine erişememesi veya yeterince kullanamaması durumu değer zinciri yönetimi açısından büyük bir tehdittir.

b) Özel Sağlık Kuruluşlarında Değer Zinciri Yönetimi: Özel sağlık kuruluşları hizmet sunmuş oldukları kişilere kamudaki kuruluşlara göre daha özel hizmet sunumu konusunda daha başarılıdır. Bu durum özel sağlık kuruluşlarının değer zinciri yönetiminde güçlü kılmaktadır. Ayrıca kamu kuruluşlarına göre özel kuruluşlarında çalışanlar arasında ilişki daha kuvvetlidir. Özel sağlık kuruluşları belirli kazanç sağlamak amacıyla getirisi yüksek olan sağlık hizmetlerine ve otelcilik hizmetlerine odaklanmaktadır. Böylece hastaların beklediği ve piyasada geçerli olan değerlerin 
ulaştırılmasına olanak sağlamaktadır. Bunların dışında özel kuruluşlarda çalışanların esnek, takım içinde çalışabilmektedir ve sağlık hizmetleri standartlarıyla ilgili sürekli eğitim almaktadır. Bireylerin kamu yerine özel sağlık kuruluşlarını tercih etmelerindeki temel sebeplerden birisi olan müşteri memnuniyeti ve geri dönüşlerin önemi konusunda özel sağlık kuruluşları daha başarılıdır ve bu durum değer zinciri yönetimi açısından önemlidir. Satış ve pazarlama işletme fonksiyonlarında özel sağlık kuruluşları rekabet ortamından dolayı daha etkili kullanılmaktadır. Özel sağlık kuruluşlarının değer zinciri yönetimi açısından önemli katkılarının yanında bazı zayıf yönleri de bulunmaktadır ve değer zinciri yönetimine zarar vermektedir. Örneğin; özel kuruluşta yer alan hekimlerin fazladan reçete yazması, daha pahalı olan ilaçların reçetelere yazılması, daha pahalı tıbbi tekniklerin hastalara sıklıkla kullanılması veya kar artışı için daha düşük kalitede hizmetlerin sunulması sorunlarıyla karşılaşmaktadır. Ayrıca belirli kazançlar elde etmek için estetik gibi sağlık hizmetleri konusunda talepler oluşturulmasına yönelik adımlar atabilmektedir ve hastaları gerektiğinden fazla sürede hastanede kalmalarına yönelik adımlar atabilmektedir. Bu durum hem hastaların sağlıklarını hem de ülkenin sağlık sistemini olumsuz yönde etkileyebilmektedir. Değer zinciri içerisinde yer alan sağlık kuruluşlarında kazan-kazan şeklinde yapılabilecek olan kamu-özel işbirliği sadece özel kuruluşlar için bir fırsat değil aynı zamanda zincirde yer alan diğer paydaşlar açısından bir firsattır. Burada dikkat edilmesi gereken nokta, bu işbirliğinin yönetim bilimi usullerine göre yapılmalıdır. Özel sağlık kuruluşları insan kaynağının hem can güvenliği hem de iş güvenliği açısında otomasyon sağlanmış teknolojik kaynakları optimal düzeyde kullanması rekabet üstünlüğünün sağlanması ve değer zinciri açısından büyük bir fırsattır. Özel sağlık kuruluşları sigorta şirketleri veya sağlık hizmetleri sunumunda yer alan diğer paydaşlar aracılığıyla hastaların talepleri doğrultusunda sağlıkta niş piyasaların ortaya çıkmasında görüşmeler yapabilme imkânı bulunmaktadır. Özel sağlık kuruluşları değer zinciri yönetimi konusundaki birçok olumlu özelliklerine rağmen dikkat etmesi gereken bazı noktalar bulunmaktadır. Finansal sürdürülebilirlik bu noktalardan birisidir. Çünkü hastalar kamu sağlık kuruluşlarında genellikle tam olarak beklentilerini karşılayamadıkları için özel kuruluşları tercih etmektedir ve özel sağlık kuruluşlarına yönelik beklentileri yüksektir. Hastalara sağlık hizmetleri konusundaki beklentileri karşılanırken finansal sürdürülebilirlik kavramı unutulmamalıdır. Eğer unutulursa finansal sürdürülebilirlik değer zinciri yönetimi ve kuruluş açısından bir tehdit halini alır. Bazı özel sağlık 
kuruluşları kamuya bağlı olan eğitim ve araştırma hastaneleri kadar ekipmana sahip olmadıkları için ciddi hastalıklar veya komplikasyonlarla mücadele eden hastaların sevk etmektedir. Bu sevk işlemleri kamudaki kuruluşların yoğunluk durumu dikkate alınmadan sevk yazılması durumu değer zinciri yönetimi açısından istenilmeyen bir durumdur ve buna dikkat edilmesi gerekir.

\section{Sonuç ve Öneriler}

Değer zinciri, bir mal veya hizmetin oluşmasında katkıda bulunan bütün tarafların optimize şekilde faaliyetlerini sürdürmelerine, olumlu sonuçların artmasına, ekonomik açıdan işbirliklerinin sağlanmasına yönelik ortaya çıkan bir kavramdır. Değer zinciri yönetimi, hizmet sunulan kişilere, paydaşlara ve sisteme belirli bir değerin katılmasını prensip edinmektedir. Sağlık hizmetlerinin sunulmasının temel amacı, toplumu oluşturan bireylerin kişilikleri, onurlarına ve değerlerine saygı göstererek ve ülkenin sağlık sistemine, sağlık kuruluşlarına, sağlık çalışanlarına ve hastalarına değer katacak şekilde sağlık düzeylerinin korunması, sağlıklarının geliştirilmesidir. Bu noktada sağlık hizmetlerinin sunumu ve değer kazanması için sadece sağlık kuruluşlarının dışında ilaç firmalarının, tıbbi cihaz şirketlerinin, sağlık bakanlığının, bilgi sistem üreticilerinin ve daha birçok kuruluşun rolü bulunmaktadır. Bu çalışmada sağlık hizmetlerinin sunulmasını sağlayan kamu ve özel sağlık kuruluşlarının değer zinciri yönetimi açısından değerlendirilmiştir.

Sağlık kuruluşlarında değer zinciri yönetiminde sektörde yer alan bütün kuruluşları genel olarak değerlendirmek doğru değildir. Bunun yerine kamu ve özel kuruluşları ayrı ayrı bir şekilde değerlendirilmelidir. Bu şekilde değerlendirmenin temel sebebi kamu ve özel kuruluşlar arasındaki farklılıklardır. Kamu sağlık kuruluşları sağlık hizmetleri sunumundaki rollerinin büyük olmasından dolayı değer zinciri yönetimi anlayışı geniştir. $\mathrm{Bu}$ sorumluluğun artmasının temel nedenleri, genel sağlık kapsamının artması, sağlık hizmetlerine erişimin kolaylaşması gibi hastalara yönelik sağlanan kolaylıklardır. Hastalara yönelik sağlanan kolaylıklar aynı zamanda kuruluşların finans yönetimini olumsuz yönde etkileyebilir. Teknolojik gelişmelerle beraber sağlık hizmet sunumunu web site, sosyal medya veya buna benzer birçok uygulamalar geliştirilmektedir ve buna benzer birçok fırsatlar ortaya çıkmaktadır. Sonuç olarak kamu sağlık kuruluşları değer zinciri yönetimini geniş kapsamda tanımlamaları çok önemlidir ancak eksik olduğu bazı noktalar bulunmaktadır. Kamu sağlık kuruluşlarının 
değer zinciri yönetimi kapsamında ve sağlık sistemine katkıda bulunmaları adına aşağıdaki önerileri uygulaması gerekir:

- Sağlık hizmetlerinin genel kapsam sayesinde toplumu oluşturan bireylere ulaştırılması değer zincirini oluşturan hastalar açısından önemlidir. Kamu sağlık kuruluşlarının bireylere ulaşmaya devam etmelidir.

- Kamu sağlık kuruluşları teçhizat, insan kaynağı gibi hizmet sunumu için ihtiyaç duyduğu kaynaklarına hızlı bir şekilde ulaşabilmektedir. Buradan elde edilen zaman kazancı, öncelikli olarak sağlık eğitimi, sağlığın geliştirilmesi gibi hem ülkenin hem de değer zincirinin sağlık boyutunda gelişmesine yönelik vakit harcanmalıdır.

- Sağlık hizmetlerine erişimin giderek kolaylaşmasıyla beraber kamu sağlık kuruluşlarının talepleri ve maliyetleri karşılamakta zorluklar çekmektedir. Bunun için kamu sağlık kuruluşlarının ve bakanlığın finans yönetimi ile talep yönetimi konuları üzerinde durması gerekir.

- Kamu sağlık kuruluşlarının web site, sosyal medya gibi teknolojik uygulamalar aracılığıyla sağlık hizmetlerinin sunulmasına yönelik çeşitlilikleri yapmaya yönelik inovatif adımlar atılmalıdır. Burada atılacak adımlar sadece sağlık sistemine katkıda bulunmaz aynı zamanda değer zinciri içerisinde yer alan paydaşlara da katkıda bulunacaktır.

- Koruyucu sağlık hizmet sunmasıyla bilinen birinci basamak düzeyindeki sağlık kuruluşlarında çalışan profesyonellerin sevk ve değer zincirinde önemli bir konumlarının bulunmaktadır. Burada çalışan kişilerin hastaların sağlık konusunda bilinçli olmalarına yönelik çalışmaları bakanlık tarafından desteklenmelidir. Ayrıca böyle bir önemli rol oynayan birinci basamak sağlık kuruluşlarında çalışan profesyonellerin ihtiyaçları ve talepleri dikkate alınmalıdır.

- Sağlık hizmetlerinin kullanımı esnasında sıkça meydana gelen olumlu ve olumsuz olaylar bir ülke veya bölgedeki sağlık hizmeti kullanım kültürünü oluşturmaktadır ve bu kültürün oluşumda ana faktör insandır. Acil servislerin gereksiz yere kullanılması, sağlıkta şiddet olayları gibi sağlıkta karşılaşılan olumsuz durumlara gerekli müdahaleler yapılmaz ise bu tür davranışlar birer alışkanlık halini alacaktır. Ayrıca insan faktörü sadece hasta boyutunda düşünülmemelidir. Sağlık 
çalışanlarının da belirli beklentileri vardır. $\mathrm{Bu}$ beklentilerin düzenlenip karşılıklarının verilmesi gerekir.

- Ayaktan tedavi hizmetlerini almış veya diğer hastalara göre daha az cerrahi müdahale geçirmiş olan hastaların hizmet aldıkları kuruluştan aynı gün içerisinde taburcu olmamalarından dolayı zaman ve kaynak kaybına yol açmaktadır. Buna benzer sorunların ortaya çlkma nedenleri incelenmelidir. Eğer bu tip sorunlarla karşılaşan kuruluşlarda sağlık hizmetleri sürecinin iyi yönetilemediği görüşü hâkim olacaktır. Burada belirtilen sorunun çözümü için sağllk yöneticileri ve bu süreçler konusunda deneyimli kişilerin sorumlu olmaları veya böyle sorunlar yaşayan kuruluşlara destek verilmesi gerekir.

- Başta Türkiye olmak üzere birçok ülkede yaşlı nüfus giderek artmaktadır. Mevcut olan sağlı hizmetlerine erişim ve kullanım sorunları düşünüldüğünde öncelikli olarak sağlık hizmetlerinin kullanımına yönelik çalışmaların yapılması gerekir. Yapılan bu çalışmanın ışı̆̆ında ileriye dönük yaşlılara yönelik sağlık hizmetlerine erişim ve kullanımına yönelik araştırmalar yapılmalıdır.

Özel sağlık kuruluşları kamu sağlık kuruluşları kadar geniş kapsamlı tanımlama yapmamasına rağmen sağlık hizmetlerini bireylere kendilerini daha özel ve daha iyi hissedecek şekilde hizmetleri sunmaya özen göstermektedir. Hastalara daha özel ve kaliteli hizmet sunmak için çalışanların ortak bir amaca yönelik hareket etmelerini sağlamaktadır ve bu konuda kamu sağlık kuruluşlarına göre daha başarılıdır. Özel sağlık kuruluşları hastalara, sağlık sistemine ve sağlıkla ilgili diğer paydaşlara değer katabilmek adına sadece sağlık hizmetleri sunumuna odaklanmaz aynı zamanda otelcilik ve buna benzer birçok boyuta odaklanmaktadır. Özel kuruluşların yaratmış olduğu bu değer kamu sağlık kuruluşları tarafından da kabul görerek yeni yapılan kamu sağlık kuruluşları otelcilik hizmeti gibi boyutlara da önem vermektedir. İşletme fonksiyonları bir örgütün düzenli bir şekilde hedeflerine ve amaçlarına ulaşmasına yardımcı olmaktadır. Özel sağlık kuruluşları rekabet ortamında mücadele etmesine bağlı olarak işletme fonksiyonları konusunda kamu sağlık kuruluşlarına göre daha bilinçlidir. Sonuç olarak özel sağlık kuruluşları değer zinciri yönetimini kamu kuruluşları kadar geniş bir şekilde tanımlamamalarına rağmen post modern yönetim anlayışının gerekliliklerini yerine getirerek değer zinciri yönetimine katkıda 
bulunmaktadır. Özel sağlık kuruluşlarının değer zinciri yönetimi kapsamında ve sağlık sistemine katkıda bulunmaları adına aşağıdaki önerileri uygulaması gerekir:

- Özel sağlık kuruluşlarının bir kısmı fazla gelir getirecek olan hizmetlere yönelik talebin oluşturulması gibi toplum sağlığını riske edecek olan faaliyetlerde bulunma eğilimi vardır. Bu eğilimin önüne geçmesi için bakanlığın hem toplumu hem de özel sağlık kuruluşlarını bilinçlendirecek şekilde müdahalesine ihtiyaç duyulmaktadır.

- Özel sağlık kuruluşlarında çalışan profesyonellerin belirli bir miktar kazanç elde etme adına etik açıdan yakışmayacak şekilde uygulamalara gitmektedir. Pahalı olan ilaçların reçetelere yazılması, gereksiz ilaç kullanımına itecek şekilde reçetelerin düzenlenmesi gibi ahlaki tehlikeye yol açabilecek uygulamalara yönelik yenilikçi çözümlere veya süreçlere yönelik araştırmaların yapılması gerekir. Çünkü özel sağlık kuruluşlarında gerçekleşen durumlar kamu sağlık kuruluşlarında çalışanlar için de geçerlidir.

- Sağllk turizminin geliştirilmesine yönelik estetik gibi bölümlerde özel sağllk kuruluşları talepler yaratmaktadır. Bu durum başta ülke sağlık sistemi açısından faydalı gözükebilir. Ancak kuruluşlar tarafından yaratılan talepler kontrol altına alınmaz ise sağlık sistemini olumsuz yönde etkileyecektir. Bundan dolayı özel sağlık kuruluşlarının sağlık turizmi gibi faaliyetler aracılığıyla talep etmeye kalkarken bakanlıktan veya danışman firmalarının görüşlerinin mutlaka alınması gerekir.

- Kamu ile özel işbirliklerinin sadece yeni hastaneler inşa edilmesine yönelik değil aynı zamanda çalışanların eğitimi gibi çok boyutlu anlamda yapılmalıdır.

- Özel sağlık kuruluşlarının finansal, pazarlama gibi işletme fonksiyonlarını kamu kuruluşlarına göre daha iyi kullanması ve yeniliklere daha açık olmalarından dolayı sağlık alanında sağlık turizmi gibi niş pazarların ortaya çımasına yönelik araştırmalarını sıklaştırması gerekir.

- Hem özel hem de kamu sağlık kuruluşlarına olan talep giderek artmaktadır. Bu durum talep yönetimi ve finansal sürdürülebilirliğin sağlanmasını zorlaştırmaktadır. Talep yönetimi, finansal yönetim gibi konulara hâkim olan ve sağlık yönetimi eğitimi almış profesyonel yöneticilerin hem kamu hem de özel sağlık kuruluşlarında yer almaları ve söz hakkı sahibi olmaları gerekir. 


\section{KAYNAKLAR}

1. Sharan AD, Schroeder GD, West ME, Vaccaro AR. Understanding a value chain in health care. Journal of Spinal Disorders and Techniques. 2015;28(8):291-293. doi: 10.1097/BSD.oooooooooooo0319.

2. Robbins SP, Decenzo DA, Coulter M. Fundamentals of Management: Essential Concepts and Applications. 8. baskı. Çev: Öğüt A. İstanbul: Nobel Yayncılık; 2016.

3. Hock Soon Q, Mohamed Udin Z. Supply chain management from the perspective of value chain flexibility: an exploratory study. Journal of Manufacturing Technology Management. 2011;22(4):506-526. doi: 10.1108/17410381111126427.

4. Burns LR, DeGraaff RA, Danzon PM, Kimberly JR, Kissick WL, Pauly MV. The Wharton School study of the health care value chain. The health care value chain: producers, purchasers and providers. San Francisco: Jossey-Bass; 2002.

5. Nishtar S. The mixed health systems syndrome. Bull World Health Organ. 2010;88(1):66-73. doi:10.2471/BLT.09.067868.

6. Torchia M, Calabrò A, Morner M. Public-private partnerships in the health care sector: a systematic review of the literature. Public Manage Rev. 2015;17(2):236-261. doi:10.1080/14719037.2013.792380.

7. Buttigieg SC, Schuetz M, Bezzina F. Value chains of public and private healthcare services in a small eu island state: A SWOT Analysis. Front. Public Health. 2016;4:201. doi: 10.3389/fpubh.2016.00201. 